\title{
Intraocular pressure following 18 hours of systemic dehydration in ocular normotensive healthy subjects
}

\begin{tabular}{|c|c|}
\hline \multicolumn{2}{|c|}{$\begin{array}{l}\text { Authors: } \\
\text { Faustina K. Idu }{ }^{1} \\
\text { Gladys O. George }{ }^{1} \\
\text { Leonard F.O. Obika² }\end{array}$} \\
\hline \multicolumn{2}{|c|}{$\begin{array}{l}\text { Affiliations: } \\
{ }^{1} \text { Department of Optometry, } \\
\text { University of Benin, Nigeria }\end{array}$} \\
\hline \multicolumn{2}{|c|}{$\begin{array}{l}{ }^{2} \text { Department of Physiology, } \\
\text { School of Basic Medical } \\
\text { Sciences, College of Medical } \\
\text { Sciences, University of Benin, } \\
\text { Nigeria }\end{array}$} \\
\hline \multicolumn{2}{|c|}{$\begin{array}{l}\text { Correspondence to: } \\
\text { Faustina Idu }\end{array}$} \\
\hline \multicolumn{2}{|c|}{$\begin{array}{l}\text { Email: } \\
\text { faustina.idu@uniben.edu }\end{array}$} \\
\hline \multicolumn{2}{|c|}{$\begin{array}{l}\text { Postal address: } \\
\text { P.M.B. 1154, Benin City, Edo } \\
\text { State 30001, Nigeria }\end{array}$} \\
\hline \multicolumn{2}{|c|}{$\begin{array}{l}\text { Dates: } \\
\text { Received: } 11 \text { Feb. } 2014 \\
\text { Accepted: } 05 \text { Dec. } 2014 \\
\text { Published: } 23 \text { July } 2015\end{array}$} \\
\hline \multicolumn{2}{|c|}{$\begin{array}{l}\text { How to cite this article: } \\
\text { Idu FK, George GO, Obika } \\
\text { LFO. Intraocular pressure } \\
\text { following } 18 \text { hours of } \\
\text { systemic dehydration in } \\
\text { ocular normotensive healthy } \\
\text { subjects. Afr Vision Eye } \\
\text { Health. } 2015 ; 74(1), \text { Art. } \\
\# 10,5 \text { pages. http://dx.doi. } \\
\text { org/10.4102/aveh.v74i1.10 }\end{array}$} \\
\hline \multicolumn{2}{|c|}{$\begin{array}{l}\text { Copyright: } \\
\text { (C) 2015. The Author(s). } \\
\text { Licensee: AOSIS } \\
\text { OpenJournals. This work is } \\
\text { licensed under the Creative } \\
\text { Commons Attribution } \\
\text { License. }\end{array}$} \\
\hline \multicolumn{2}{|l|}{ Read online: } \\
\hline 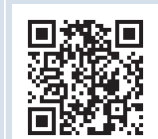 & $\begin{array}{l}\text { Scan this QR } \\
\text { code with your } \\
\text { smart phone or } \\
\text { mobile device } \\
\text { to read online. }\end{array}$ \\
\hline
\end{tabular}

Aim: To investigate the effect of dehydration on intraocular pressure (IOP).

Subjects: The study population comprised 50 subjects ( 27 men and 23 women) with a mean age of $42.84 \pm 2.64$ years.

Method: The subjects dehydrated for 18 hours. IOP was assessed in both eyes using the Perkins handheld applanation tonometer. Baseline measurement of IOP was taken before the subjects dehydrated for 18 hours and repeated after dehydration. Blood samples were taken before and after dehydration for the determination of plasma osmolality and plasma antidiuretic hormone $(\mathrm{ADH})$ concentrations.

Results: A statistically significant $(p<0.001)$ reduction in the mean weight of subjects occurred after dehydration. There was a significant reduction in IOP from $16.68 \mathrm{mmHg} \pm$ $0.32 \mathrm{mmHg}$ to $13.08 \mathrm{mmHg} \pm 0.31 \mathrm{mmHg}$ after dehydration $(p<0.001)$. Mean plasma osmolality showed a statistically significant increase $(p<0.05)$ from baseline of $290.02 \mathrm{mOsmol} / \mathrm{kg} \pm$ $1.25 \mathrm{mOsmol} / \mathrm{kg}$ to $294.96 \mathrm{mOsmol} / \mathrm{kg} \pm 1.33 \mathrm{mOsmol} / \mathrm{kg}$ after dehydration. There was also a significant increase $(p<0.05)$ in mean plasma ADH concentration from $5.36 \mathrm{pg} / \mathrm{mL} \pm$ $0.21 \mathrm{pg} / \mathrm{mL}$ to $6.40 \mathrm{pg} / \mathrm{mL} \pm 0.20 \mathrm{pg} / \mathrm{mL}$ after dehydration. There were no significant differences in both systolic and diastolic blood pressures before and after dehydration.

Conclusion: Dehydration decreases IOP in healthy humans; this decrease probably results from an increase in plasma osmolality and plasma ADH concentrations.

\section{Introduction}

Dehydration is a condition where there is inadequate fluid to fill the compartments of the body as a result of decreased intake, lack of drinking water, and increased excretion through the skin, lungs, kidneys and gastrointestinal tract. ${ }^{1}$ The role of hydration in the maintenance of health is increasingly recognised. A study in healthy adults shows that even mild dehydration impairs a number of important aspects of cognitive function. ${ }^{2}$ A substantial proportion of the population is chronically dehydrated, and even mild dehydration may be a cause of many health problems, including dry eyes. ${ }^{3}$ Many people drink large volumes of coffee, tea, alcohol and sodas that act as diuretics and can bring on a dehydrated state. Many people are also on medications that further increase the risk of dehydration. ${ }^{3}$

Water is lost from the body in varying amounts via a number of different routes: the main avenues of daily water loss are urine (about $1400 \mathrm{~mL}$ ), faeces $(200 \mathrm{~mL}$ ), insensible losses from the lungs $(400 \mathrm{~mL})$ and loss via the skin $(500 \mathrm{~mL})$. The total daily water loss is therefore about $2500 \mathrm{~mL}$, but this varies greatly amongst individuals and also depends on environmental conditions. ${ }^{4}$

It has been established that plasma osmolality and plasma antidiuretic hormone (ADH) levels provide an index of the degree of dehydration. ${ }^{5}$ An increase in plasma osmolality as seen in dehydration is a major stimulus for the release of $\mathrm{ADH}$. ADH concentrations are elevated during dehydration owing to alterations in extracellular fluid volume and tonicity. Osmoreceptors located in the vicinity of the AV3V region and the supraoptic nuclei are excited by minute increases in extracellular fluid osmolality. ${ }^{1}$ Increases in plasma osmolality as seen in dehydration cause fluid to be pulled by osmosis out of the osmoreceptors, decreasing their size and initiating appropriate signals in the hypothalamus to cause the release of $\mathrm{ADH}$ by the magnocellular neurons. Plasma osmolality and change in body mass have been reported to be some markers of dehydration assessment. ${ }^{6,7}$ A value of $295 \mathrm{mOsmol} / \mathrm{kg}$ plasma osmolality has been reported as the upper population-based limit for dehydration. ${ }^{8}$

Normal intraocular pressure (IOP) is essentially maintained by the dynamic equilibrium between the rate at which aqueous humour enters the eye (inflow) and the rate at which it leaves the 
eye (outflow). IOP within the normal population is within the range of $11 \mathrm{mmHg}$ to $21 \mathrm{mmHg}$ (mean $16 \mathrm{mmHg} \pm$ $2.5 \mathrm{mmHg}){ }^{9}$ Many researchers have reported a decrease in IOP as a result of dehydration induced by exercise and by fasting. 10,11,12 The present study was therefore aimed at investigating the effect of dehydration on IOP.

\section{Materials and methods}

We conducted a prospective experimental study in the Department of Optometry, University of Benin, Benin City, and the Department of Chemical Pathology, University of Benin Teaching Hospital, Benin City, Nigeria.

\section{Subjects}

The study population comprised 50 healthy subjects ( 27 men and 23 women) between the ages of 21 and 70 years who dehydrated for 18 hours. They included staff and students of the University of Benin, Benin City, and staff of the Specialist Hospital Benin City, both in Nigeria. Informed consent was obtained from each participant after a detailed explanation of the study procedure. The study was approved by the Ethics Committee of the Specialist Hospital Benin City and was performed in accordance with the guidelines of the Declaration of Helsinki.

\section{Inclusion criteria}

Subjects included in the study were healthy, with no history of systemic diseases such as hypertension and diabetes, and ocular diseases such as glaucoma, cataract and uveitis that are responsible for raised IOP. Subjects with IOP $>21 \mathrm{mmHg}$, a history of current or prior use of topical and systemic medications within 30 days of the study, pregnant women and subjects with blood pressure $>140 / 90$, were excluded from the study. First-degree relatives of glaucoma patients were also excluded.

\section{General procedures}

A brief case history was taken to provide information on the subjects' ocular and general health. Visual acuity tests were carried out using Snellen's chart. External eye examinations were carried out using the slit lamp biomicroscope (Zeiss, USA) to rule out ocular surface and anterior segment abnormalities. The internal structures of the eye were examined with the use of monocular direct ophthalmoscope (Keeler, UK) to rule out diseases of the posterior segment. Blood pressure measurements were taken with a sphygmomanometer to rule out hypertensive patients from this research study.

Subjects who met the inclusion criteria were recruited for the study and served as their own controls. The study occurred during the rainy season so as to promote compliance, as opposed to the dry season when perception of thirst might have been a greater factor.

\section{Measurement of intraocular pressure}

A Perkins handheld tonometer was calibrated before use on subjects. All IOP measurements were taken by an independent observer who was not one of the researchers and who did not know the subjects' state of hydration. The prism surface of the Perkins held tonometer was cleaned using cotton wool moistened with methylated spirits. Subjects were comfortably seated in the examination chair with their head supported by the chair headrest. A fluorescein strip was then moistened with a small drop of anaesthetic $(0.5 \%$ tetracaine). One drop of anaesthetic was instilled into the subject's eye, who was asked to look up while the inside of the lower eyelid was gently touched with the moistened strip. The subject was then asked to look ahead, while opening both eyes wide. With the thumb, the subject's top eyelid was gently held up taking care not to put pressure on the globe. The blue light from the tonometer was directed onto the prism head and the tonometer was moved slowly until the prism rested slightly on the patient's corneal surface. The calibrated dial of the tonometer was then turned on until the two fluorescein semicircles in the prism head were seen to just touch each other. The reading at this point was noted on the measuring dial, and recorded as the IOP. The prism was then withdrawn from the corneal surface. The procedure was carried out for both eyes. Three readings were taken per eye and the averages recorded as the IOP. IOP measurements were taken at about the same time (beginning at 09h00), both before and after dehydration.

\section{Blood sample preparation and handling}

Blood samples were drawn from the antecubital vein of each subject for determination of plasma $\mathrm{ADH}$ concentration, plasma osmolality, plasma sodium and potassium concentrations, plasma urea and glucose concentrations. Samples were sent to the laboratory within 30 minutes of collection.

\section{Dehydration protocol \\ Day 1}

Each subject was given $500 \mathrm{~mL}$ of distilled water to drink to ensure that they all had approximately uniform hydration. Thirty minutes post ingestion of distilled water, baseline parameters were taken. The weight of each subject was taken and, while seated comfortably in the examination room, a baseline blood pressure measurement was also taken. Baseline IOP measurements were taken as described. Blood samples were taken from each subject for determination of baseline plasma osmolality and plasma concentration of ADH. IOP measurements were taken from 09h00.

Subjects were requested to abstain from fluid (liquid food, water, juice and beverages) for a period of 18 hours starting from $15 \mathrm{~h} 00$ on the first day to $09 \mathrm{~h} 00$ the following day. ${ }^{13}$ They were instructed to take only solid food for dinner and not to eat anything at all before presenting for the study the following morning. 
Participants were given a calibrated container each into which they passed all their urine during the 18-hour dehydration period. ${ }^{13}$

\section{Day 2}

Subjects came into the clinic by $09 \mathrm{~h} 00$ the next day with the urine samples collected during the period of dehydration. The extent of dehydration was then determined by the urine volume. Two participants whose urine volume was above $300 \mathrm{~mL}$ were excluded from the study. ${ }^{13,14}$

All procedures carried out on day 1 in the clinic were repeated. Post-dehydration weight of each subject was taken and, with each subject seated comfortably in the examination room, blood pressure and IOP measurements were taken. Blood samples were taken from each subject for determination of post-dehydration plasma osmolality and plasma ADH.

\section{Hormonal assay}

Plasma concentrations of ADH were assessed using Assay Designs' arginine vasopressin enzyme immunoassay (EIA) kit (Ann Arbor, MI. Catalog No. 900-017, Lot No. 08040908).

\section{Plasma osmolality}

Plasma osmolality was determined by the calculated method of the summation of urea, glucose and twice sodium and potassium as shown below:

- Calculated osmolality $(\mathrm{mOsmol} / \mathrm{kg})=2 \mathrm{Na}+2 \mathrm{~K}+$ glucose + urea (all in mmol/L). ${ }^{15}$

\section{Plasma sodium and potassium}

Flame photometry was used for the estimation of sodium and potassium in plasma.

\section{Statistical analyses}

All data obtained in this study were analysed using SPSS 17.0 (SPSS Inc., Chicago, IL, USA) and STATGRAPHICS Centurion XVI (Dayton, OH, USA). Pre-dehydration and post-dehydration results were analysed using the paired $t$-test to determine the effects of dehydration on IOP, plasma osmolality and plasma $\mathrm{ADH}$ concentration. Unpaired $t$-tests were used to determine significant differences in means of parameters measured in men and women. Results were presented as means and standard error of means. Significance was declared when probability values were $p<0.05$.

\section{Results}

An unpaired $t$-test showed no statistically significant difference in IOP of both the right and left eyes $(p>0.05)$ and data were therefore presented for right eyes only. The mean age of all participants $(N=50)$ was $42.84 \pm 2.64$ years; mean age for men $(N=27)$ was $43.04 \pm 2.62$ years whilst that for women $(N=23)$ was $42.65 \pm 2.66$ years.

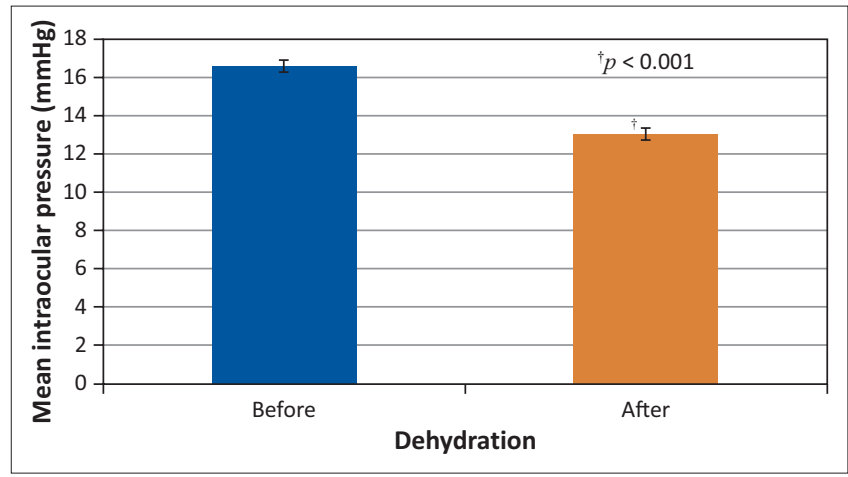

FIGURE 1: Mean intraocular pressure before and after dehydration in the study sample. A paired $t$-test showed a statistically significant reduction $(p<0.001)$ in mean intraocular pressure from the baseline value of $16.68 \mathrm{mmHg} \pm 0.32 \mathrm{mmHg}$ to $13.08 \mathrm{mmHg} \pm 0.31 \mathrm{mmHg}$ after dehydration.

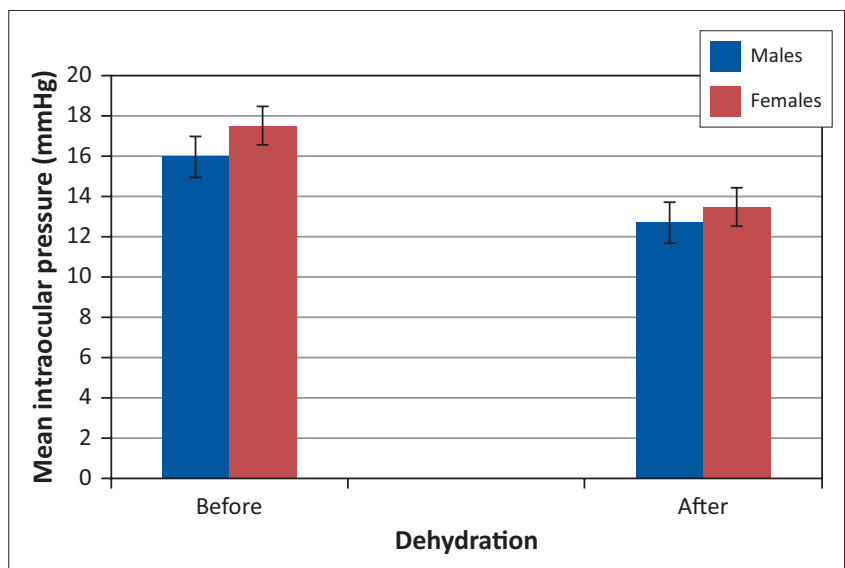

FIGURE 2: Mean intraocular pressure in men $(N=27)$ and women $(N=23)$ before and after dehydration. There was no statistically significant difference between mean IOP intraocular pressure in men and women both before and after dehydration $(p>0.05)$

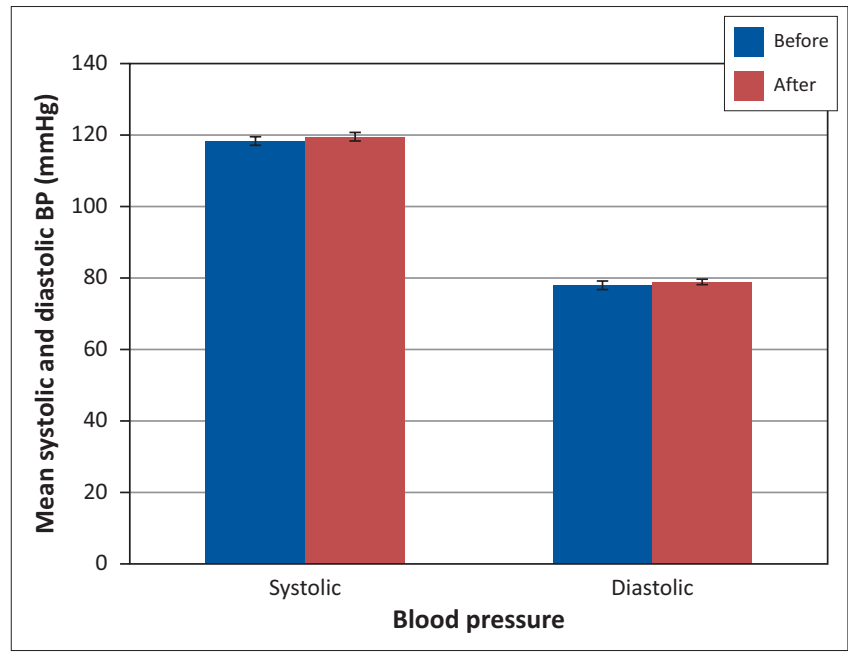

FIGURE 3: Mean systolic and diastolic blood pressures before and after dehydration in 50 participants. There were no statistically significant differences in both mean systolic and mean diastolic blood pressures after dehydration $(p>0.05)$.

The mean weight of all participants $(N=50)$ was $69.42 \mathrm{~kg}$ $\pm 1.74 \mathrm{~kg}$ before dehydration and $67.54 \mathrm{~kg} \pm 1.75 \mathrm{~kg}$ after dehydration. A paired $t$-test showed a statistically significant reduction $(p<0.001)$ in the mean weight of subjects after dehydration. 


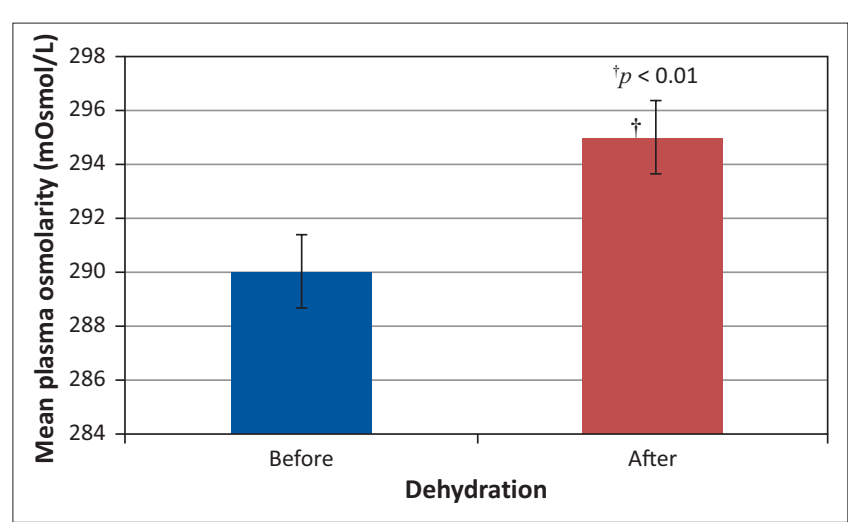

FIGURE 4: Mean plasma osmolality before and after dehydration in 50 participants. A paired $t$-test showed a significant increase $(p<0.01)$ in mean plasma osmolality from the baseline value of $290.02 \mathrm{mOsmol} / \mathrm{kg} \pm 1.25$ $\mathrm{mOsmol} / \mathrm{kg}$ to $294.96 \mathrm{mOsmol} / \mathrm{kg} \pm 1.33 \mathrm{mOsmol} / \mathrm{kg}$ after dehydration.

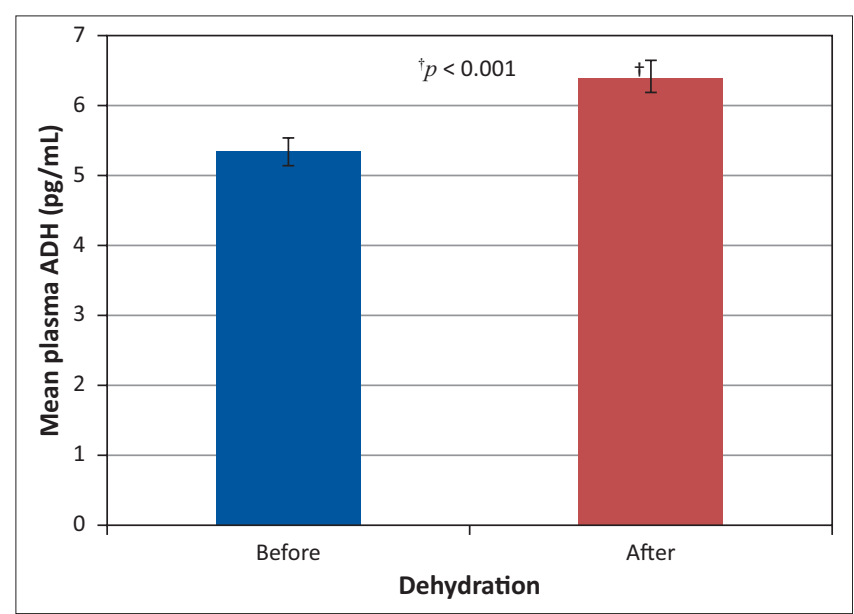

FIGURE 5: Mean plasma antidiuretic hormone concentration before and after dehydration in 50 participants. A paired $t$-test showed a significant increase $(p<0.001)$ in mean plasma antidiuretic hormone from the baseline value of $5.36 \mathrm{pg} / \mathrm{mL} \pm 0.21 \mathrm{pg} / \mathrm{mL}$ to $6.40 \mathrm{pg} / \mathrm{mL} \pm 0.20 \mathrm{pg} / \mathrm{mL}$ after dehydration.

\section{Discussion}

The study recorded a statistically significant reduction $(1.88 \mathrm{~kg})$ in weight of subjects after dehydration, which indicates that theywereindeed dehydrated $(69.42 \mathrm{kgv} .67 .54 \mathrm{~kg}$, $p<0.0001)$. This finding is consistent with those of Dadeya et al., ${ }^{10}$ who reported a weight loss of $0.4 \mathrm{~kg}-1.8 \mathrm{~kg}$ following dehydration. Another researcher also reported a body weight loss of $2 \%-3 \%$ after dehydration, which is indicative of slight dehydration. ${ }^{16}$ Dehydration is a condition that occurs when there is loss of body water. ${ }^{7}$

The study also showed that statistically significant dehydration reduced IOP from $16.68 \mathrm{mmHg}$ to $13.08 \mathrm{mmHg}$ $(p<0.001)$, as shown in Figure 1. This finding is consistent with those of Dadeya et al. ${ }^{10}$ who reported a decrease in IOP following dehydration. They postulated that the reason for decreased IOP after dehydration was that reduced water intake causes reduced aqueous formation and therefore a decrease in IOP. The results of this study are also consistent with the findings of Ashkenazi et al. ${ }^{11}$ who reported a decrease in IOP following dehydration from strenuous exercise. Hunt et al. $^{12}$ also reported a decrease in IOP during a period of exercise causing dehydration, but maintained stable IOP when hydration was restored. Our subjects, however, did not do any strenuous exercise, and there was no significant difference in IOP between the men and women, both before and after dehydration, as shown in Figure 2.

\section{Mechanism of intraocular pressure reduction by dehydration}

Increased plasma osmolality as seen in dehydration is a major stimulus of ADH release. Increased plasma osmolality in dehydration brings about an osmotic disequilibrium between plasma and aqueous humour, which shifts water from the aqueous humour into plasma, causing ocular dehydration and consequently decreasing IOP. ${ }^{11}$

Normal IOP is basically maintained by the dynamic equilibrium between the rate at which aqueous humour enters the eye (inflow) and the rate at which it leaves the eye (outflow). If, for any reason, there is an imbalance in the rate of production and outflow, IOP will be affected. If drainage is hindered, IOP increases; and if there is inadequate production, IOP reduces. Most of the aqueous humour formed travels by the help of conventional currents from the posterior chamber, out through the pupil and into the anterior chamber, from where it moves down to the filtration angle and is eventually drained by the trabecular meshwork. The drained fluid enters the Canal of Schlemm and is conducted into the episcleral venous system into the plasma.

In addition, the reduction of IOP could also be explained by the mechanism of reduced aqueous secretion by the nonpigmented ciliary epithelium. Inan et al., ${ }^{17}$ in a study using colour-doppler ultrasound of the central retinal artery, showed that after 14 hours of dehydration there was a decreased ocular blood flow in the ophthalmic artery, central retinal artery and temporal short posterior ciliary artery. Bogner et al. ${ }^{18}$ also reported decreased choroidal blood flow in rabbits. The secretion of aqueous humour is dependent on the quantity of blood passing through the nonpigmented ciliary epithelium through the ciliary artery at any given time. ADH released in dehydration could cause a slight vasopressor effect on the ciliary artery through its action on V1 receptors, thereby reducing blood flow through this artery. This reduced blood flow in the ciliary artery leads to a decrease in the active secretion of aqueous humour from the nonpigmented ciliary epithelium which will eventually reduce IOP.

It has been reported that $\mathrm{ADH}$ application causes an increase in mean arterial pressure and a decrease in IOP, indicating significantly reduced blood flow and vasoconstriction in the ocular tissues. ${ }^{18}$ The same study showed a very slight increase in both mean systolic and mean diastolic blood pressures after dehydration, although these differences were not statistically significant (Figure 3). Studies by Woods and Johnson ${ }^{19}$ found that normal long-Evans rats, when dehydrated, showed maintenance of normal systolic blood pressure that was associated with a progressive rise in plasma $\mathrm{ADH}$ concentration, a fall in body weight, and a rise in plasma and urine osmolality. They suggested from 
their results that both the antidiuretic and vasoconstrictor properties of vasopression are important in the cardiovascular response to dehydration. Similarly, Brand et al., ${ }^{20}$ in a study to determine the support of arterial blood pressure by major pressor systems in conscious dogs, showed that dehydration increases the role of $\mathrm{ADH}$ in controlling blood pressure. Hofbauer et al. ${ }^{21}$ also showed that the vasopressor effect of $\mathrm{ADH}$ contributes to the maintenance of blood pressure.

The present study showed a statistically significant increase in mean plasma osmolality and mean plasma $\mathrm{ADH}$ concentration after dehydration, as shown in Figures 4 and 5 respectively. Within the ocular tissues, AQP 1 is located in the nonpigmented ciliary epithelium responsible for aqueous secretion and therefore facilitates the movement of water across this ocular epithelium. The role of $\mathrm{ADH}$ in regulating these channels is, however, unknown.

Possible limitations of this study include, firstly, that there was no matched control group. Subjects were in a sense their own controls but IOP was measured only over 2 days; measuring IOP over 3 days would have been preferable, that is, without dehydration from day 1 to 2 and then with dehydration from day 2 to 3 . Secondly, IOP measurements were obtained when the semi-circular miresjust touched or were in alignment rather than when the inner edges of the mires slightly overlapped. Consequently, all IOP measurements would be consistently underestimated. This measurement bias affected both the pre- and post-dehydration measurements but probably would not have changed the outcomes in terms of statistical tests of significance such as the $t$-tests. Lastly, subjects were regarded as reputable volunteers who would fully co-operate in terms of restricting fluid intake and collection of their urine samples during their period of dehydration. We therefore relied on their honesty and co-operation, but we believe that our results were unlikely to have been affected to any great extent through non-compliance.

\section{Conclusion}

It is concluded from this study that dehydration decreases IOP in humans, and that this decrease may be the result of an increase in plasma osmolality and plasma $\mathrm{ADH}$ concentrations during dehydration.

\section{Competing interests}

The authors declare that they have no financial or personal relationships which may have inappropriately influenced them in writing this article.

\section{Authors' contributions}

F.K.I. (University of Benin) was the project leader and performed most of the experiments. G.O.G. (University of Benin) made conceptual contributions and performed some of the experiments. L.F.O.O. (University of Benin) was responsible for experimental and project design.

\section{References}

1. Guyton AC, Hall JF. Textbook of medical physiology. 10th ed. Philadelphia: WB Saunders, Pennsylvania, 2000; p. 3269.

2. Ritz $P$, Berrut $G$. The importance of good hydration for day-to-day health. Nutrition Rev. 2005;63:S6-13. http://dx.doi.org/10.1111/j.1753-4887.2005.tb00155.x

3. Lange M. Dehydration and dry eyes. Dry Eye Nutrition. 2013 [cited May 2013]. Available from: http//www.dryeyenutrition.net

4. Maughan RJ. Impact of mild dehydration on wellness and on exercise performance. Eur J Clin Nutr. 2003;57:S19-23. http://dx.doi.org/10.1038/sj.ejcn.1601897

5. Trewhella $M$, Forsling $M$, Richards $D$, Dawson P. Dehydration, antidiuretic hormone and the intravenousurogram. Br J Radiol. 1987;60:445-447. http:// dx.doi.org/10.1259/0007-1285-60-713-445

6. Cheuvront SN, Ely BR, Kenefick RW, Sawka MN. Biological variation and diagnostic accuracy of dehydration assessment markers 1-4. Am J Clin Nutr. 2010;92: 565-573. http://dx.doi.org/10.3945/ajen.2010.29490

7. Shirreffs SM. Markers of hydration status. Eur J Clin Nutr. 2003;57:S6-9. http:// dx.doi.org/10.1038/sj.ejcn.1601895

8. Feig PU, McCurdy DK. The hypertonic state. N Engl J Med. 1977;297:1444-1454. http://dx.doi.org/10.1056/NEJM197712292972608

9. Kanski JJ. Clinical ophthalmology: A systemic approach. 5th edn. London: Butterworth Heineman, 2003; pp. 193-198.

10. Dadeya S, Kamlesh, Shibal F, Khurana C, Khanna A. Effect of religious fasting on intra-ocular pressure. Eye. 2002;16:463-465. http://dx.doi.org/10.1038/ sj.eye.6700089

11. Ashkenazi I, Melamed S, Blumenthal M. The effect of continuous strenuous exercise on intraocular pressure. Invest Ophthalmol Vis Sci. 1992;33:2874-2877.

12. Hunt AP, Feigi B, Stewart IB. The intraocular pressure response to dehydration: A pilot study. Euro J Appl Physiol. 2012;112:1963-1966. http://dx.doi.org/10.1007/ s00421-011-2143-5

13. Obika LFO, Idu FK, George GO, Ajayi OI, Mowoe RS. Thirst perception and drinking in euhydrate and dehydrate human subjects. Nig J Physiol Sci. 2009;24:25-32. http://dx.doi.org/10.4314/njps.v24i1.46377

14. Maughan RJ. Hydration, morbidity, and mortality in vulnerable populations. Nutr Rev. 2012;70:S152-155. http://dx.doi.org/10.1111/j.1753-4887.2012.00531.x

15. Purssell RA, Pudek M, Brubacher J, Abu-Laban RB. Derivation and validation of a formula to calculate the contribution of ethanol to the osmolality gap. Ann Emerg Med. 2001;38:653-659. http://dx.doi.org/10.1067/mem.2001.119455

16. Kayikcioglu O, Guler C. Religious fasting and intra-ocular pressure. J Glaucoma. 2000;9:413-414. http://dx.doi.org/10.1097/00061198-200010000-00011

17. Inan UU, Yucel A, Ermis SS, Ozturk F. The effect of dehydration and fasting on ocular blood flow. J Glaucoma. 2002;11:411-415. http://dx.doi.org/10.1097/00061198200210000-00007

18. Bogner B, Tockner B, Runge C, et al. The effect of vasopressin on choroidal blood flow, intraocular pressure and orbital venous pressure in rabbits. Invest Opthalmol Vis Sci. 2011;52:7134-7140. http://dx.doi.org/10.1167/iovs.11-7791

19. Woods RL, Johnson Cl. Contribution of vasopressin to maintenance of blood pressure during dehydration. Am J Physiol. 1983;245:F615-621.

20. Brand PH, Metting PJ, Britton SL. Support of arterial blood pressure by major pressor systems in conscious dogs. Am J Physiol. 1988;255:H483-H491.

21. Hofbauer KG, Studer W, Mah SG, Michel JB, Wood JM, Stalder R. The significance of vasopressin as a pressor agent. J Cardiovasc Pharmacol. 1984;6:S279-464. http://dx.doi.org/10.1097/00005344-198406002-00018 